Original Article

\title{
The effects of Juchumseogi and Juchumseo Jireugi motions of taekwondo on muscle activation of paraspinal muscles
}

\author{
Jongmyeng BAeK ${ }^{1)}$, JAESEOK LeE ${ }^{1)}$, JonghyUn KIM ${ }^{1)}$, JEONGHUn KIM ${ }^{1)}$, \\ Dongwook Han, PhD, $\mathrm{PT}^{1)^{*}}$, Sunghak Byun, PhD ${ }^{2}$ \\ 1) Department of Physical Therapy, College of Health and Welfare, Silla University: 700 Beon-gil, 140 \\ Baegyang-daero, Sasang-gu, Busan 617-736, Republic of Korea. \\ 2) Good Posture Association, Republic of Korea
}

\begin{abstract}
Purpose] The purpose of this study is to examine the effects of Juchumseogi and Juchumseo Jireugi motions on muscle activation of the paraspinal muscles. [Subjects] The subjects of this study were 20 healthy male students who listened to an explanation of the study methods and the purpose of the experiment, and agreed to participate in the study. [Methods] Muscle activation measurements of the paraspinal muscles at C3, T7, and L3 were taken while standing still and while performing Juchumseogi and Juchumseo Jireugi movements. The Juchumseogi and Juchumseo Jireugi motions were performed 3 times, and its mean value was used for analysis. [Results] The right and left muscle activation of paraspinal muscles induced by Juchumseogi and Juchumseo Jireugi motions in C3 and T7 were significantly higher than those induced by just standing. Muscle activation of paraspinal muscles induced by Juchumseo Jireugi motions in C3, T7, and L3 were significantly higher than those induced by Juchumseogi alone. The right and left muscle activation of paraspinal muscles induced by Juchumseo Jireugi motion in C3, T7, and L3 were significantly higher than those induced by standing and Juchumseogi alone. [Conclusion] This study demonstrated that Juchumseogi and Juchumseo Jireugi motions of Taekwondo could increase muscle activation of paraspinal muscles, and Juchumseo Jireugi motions were more effective for enhancing muscle activation of paraspinal muscles.
\end{abstract}

Key words: Taekwondo, Paraspinal muscles, Muscle activation

(This article was submitted Apr. 21, 2015, and was accepted Jun. 3, 2015)

\section{INTRODUCTION}

Taekwondo has grown as a global martial art sport, and is now being trained in 188 countries all over the world. In addition, the value of Taekwondo competition as a sport has been so widely acknowledged as to be adopted as a formal event 4 consecutive times in the Olympic Games ${ }^{1)}$. Taekwondo as a martial art sport aims at body training, and Taekwondo students are increasing not only in Korea but also throughout the world. The basic techniques of Taekwondo are Poomsae, sparring, smashing, and self-defense. Taekwondo movements can be categorized as standing, defending, Jireugi, thrusting, hitting, kicking, and avoiding ${ }^{2)}$. Because the basic motions of Taekwondo are moderate, they are considered effective for increasing muscle strength and improving coordination. In spite of this however, most studies undertaken involving Taekwondo have been focused only

*Corresponding author. Dongwook Han (E-mail: dwhan@ silla.ac.kr)

(C2015 The Society of Physical Therapy Science. Published by IPEC Inc. This is an open-access article distributed under the terms of the Creative Commons Attribution Non-Commercial No Derivatives (by-ncnd) License $<$ http://creativecommons.org/licenses/by-nc-nd/3.0/>. on its history or philosophy, or on Taekwondo skills including biomechanical analyses of kicking, kicking frequency, and scoring ${ }^{3)}$. In line with this, $\mathrm{Choi}^{4)}$ performed a research study comparing impact power depending on target distance and Jireugi mode at the time of Juchumseo Jireugi motion. Park ${ }^{5)}$ performed a biomechanical analysis for Juchumseo Jireugi based on types of motion. Kang et al. $\left.{ }^{6}\right)$ performed research on comparative analysis of biomechanical variables of Juchumseo Jireugi, also depending on types of motion. Park ${ }^{7)}$ performed a motor-mechanic analysis for Juchumseo Jireugi. $\mathrm{Ahn}^{8)}$ performed an imagery analysis of motor control features of Stop-Jireugi and Push-Jireugi. Lee et al. ${ }^{9)}$ carried out a research study on the relevance of lumbar extension muscles and quick Juchumseo Jireugi motions. Therefore, most research involving Taekwondo focuses on the enhancement of athletic performance in terms of sports. On the other hand, research on the effects of an exercise program using basic motions of Taekwondo on body training has thus far been unsatisfactory. More specifically, in spite of the fact that exercise programs applying Taekwondo to strengthening specific parts of body have been developed and distributed, research proving the effects of an exercise program using basic motions of Taekwondo has thus far proved insufficient. Recently, a few researchers have been exploring the effects of exercise aiming at body training 
using motions of Taekwondo. Byeon et al. ${ }^{10)}$ performed research exploring whether an exercise program applying Taekwondo motions would be effective for postural correction, and as a result, they reported that such a program would be effective for postural correction. However the disadvantage of that study was that the postural correction effects of Taekwondo were not specifically studied. Therefore, the benefits of an exercise program using Taekwondo motions to cause desirable changes in relevant muscles were not demonstrated. Park ${ }^{11)}$ performed a research study on the effects of Juchumseogi motions of Taekwondo Poomsae on muscle activation of the lower limbs such as the biceps femoris, rectus femoris, and gastrocnemius, and as a result, he reported that muscle activation of lower limb muscles was increased. Finally, Park ${ }^{11}$ ) proved that Taekwondo motions could change muscle activation of relevant muscles, and that they are also effective for increasing muscle strength. However, if upper limb exercises of Jireugi are combined with Juchumseogi motions, it is expected that muscle strength of lower limbs and muscle activation of paraspinal muscles could be improved. Upright Juchumseogi posture requires upright spinal alignment which also requires muscle activation of paraspinal muscles. Therefore, in order to perform Jireugi motion moderately, spinal fixation is essential because it is enabled only when paraspinal core muscles are activated. Therefore, this study researched the effects of Juchumseogi, a basic motion of Taekwondo, and Jireugi, a basic motion of the upper limbs, on the muscle activation of paraspinal muscles. This information should be useful in the development of an exercise program applying Taekwondo motions to improve the strength of paraspinal muscles and improve posture.

\section{SUBJECTS AND METHODS}

This study was performed utilizing 20 male university students attending S university located at Busan. This study complied with the ethical standards of the Declaration of Helsinki, and written informed consent was received from each participant. All the test subjects had no past medical record of musculoskeletal disease that could impede Juchumseogi and Jireugi motions. Muscle activation was measured using surface electromyography (Keypoint, Medtronic, USA). A disposable unipolar surface electrode $(\mathrm{W}: 1.5 \mathrm{~cm}, \mathrm{~L}$ : $2.5 \mathrm{~cm}$ ) was used, and the ground electrode was a unipolar surface electrode with a diameter of $3 \mathrm{~cm}^{12)}$. The sampling rate of muscle activation signals was set as $1,000 \mathrm{~Hz}$ and a frequency band of $20-1,000 \mathrm{~Hz}$ and a $50 \mathrm{~Hz}$ notch filter were used. The muscle activation measuring sites of paraspinal muscles at the time of Juchumseogi and Juchumseo Jireugi movements were C3, T7 and L3. The small electrode attachment site was indicated with an oil-based pen. In order to reduce skin resistance against the surface electromyogram signal, the surface electrode was applied with a small amount of electrolyte gel, and was attached to the skin after removing skin fat and the cornified layer of skin with sterilization alcohol and by rubbing the attachment site with fine sandpaper 3-4 times. The active electrode was attached to the right and left paraspinal muscles $1 \mathrm{~cm}$ from the spinous process of $\mathrm{C} 3, \mathrm{~T} 7$ and $\mathrm{L} 3$, and the ground electrode site was located at the sacrum. In order to ensure measurement standardization, all the test subjects were made to stand on a rubber plate with their feet placed squarely on a foot-shaped mark. The standing position was adjusted by using a hitting plate so that the subject's fist would be positioned at the solar plexus at the time of Jireugi. The reference value for muscle activation standardization was measured at righting posture. Righting posture is a comfortable standing posture spreading two legs at shoulder width and naturally attaching the upper limb on the waist. Subsequently, muscle activation during Juchumseogi motion was measured. Juchumseogi posture is a preparatory posture of Taekwondo in which the subject maintains a forward-facing position while standing tiptoe with the toes pointing outward and legs spread beyond the width of the shoulders. The knee was slightly bent and the hip was prevented from jutting out in a backward direction. The upper limb was positioned at the waist by lightly bending the shoulder joint after bending the elbow joint at 90 degrees while clenching the fist. At this point muscle activation was measured while performing Jireugi motion in the Juchumseogi posture. Juchumseo Jireugi motion is a stretching out of the fist forward quickly and moderately. All measurements were performed 3 times, and the mean value was used for an analysis. When measurements were taken while changing posture, a break time of 30 seconds was given. The value used for analysis was the ratio of muscle activation at the time of Juchumseogi and Juchumseo Jireugi motions, based on muscle activation during standing posture. In order to examine the difference of muscle activation depending on postural change by using estimated value, repeated measure ANOVA was performed; to examine the difference between groups, paired t-test was used. Statistic program used for this study was SPSS for windows software (ver. 21.0) and a significance level was $\alpha=0.05$.

\section{RESULTS}

Table 1 shows the effects of Juchumseogi and Juchumseo Jireugi on muscle activation of paraspinal muscles. In the right and left $\mathrm{C} 3$ paraspinal muscle, the muscle activation differed significantly from the postures $(\mathrm{p}<0.05)$. The muscle activation of the right $\mathrm{C} 3$ paraspinal muscle in standing posture was $100 \%$; in Juchumseogi, it was $127.5 \%$; in Juchumseo Jireugi, it was $239.7 \%$. The muscle activation of the left $\mathrm{C} 3$ paraspinal muscle in standing posture was $100 \%$; in Juchumseogi, it was $128.9 \%$; in Juchumseo Jireugi, it was $269.3 \%$. The levels of muscle activation of the right and left C3 paraspinal muscle induced by Juchumseogi $(\mathrm{p}<0.05)$ and Juchumseo Jireugi motion $(\mathrm{p}<0.05)$ were higher than those induced by standing posture. Futhermore, muscle activation of the right and left C3 paraspinal muscle in Juchumseo Jireugi was significantly higher than that induced by Juchumseogi $(p<0.05)$. In the right and left T7 paraspinal muscle, the muscle activation differed significantly from the postures $(p<0.05)$. The muscle activation of the right T7 paraspinal muscle in standing posture was $100 \%$; in Juchumseogi, it was 209.3\%; in Juchumseo Jireugi, it was $517.6 \%$. Muscle activation of the left T7 paraspinal muscle in standing posture was $100 \%$; in Juchumseogi, it was $163.5 \%$; in Juchumseo Jireugi, it was $375.1 \%$. The levels of 
Table 1. The effects of Juchumseogi and Juchumseo Jireugi motion on muscle activation of paraspinal muscles (\%)

\begin{tabular}{llccc}
\hline Location & & Standing & Juchumseogi & Juchumseo Jireugi \\
\hline \multirow{3}{*}{ Right } & Cervical* $^{*}$ & $100.0 \pm 0.0$ & $127.5 \pm 39.2^{\mathrm{a}}$ & $239.7 \pm 76.9^{\mathrm{bc}}$ \\
& Thoracic* $^{*}$ & $100.0 \pm 0.0$ & $209.3 \pm 202.6^{\mathrm{a}}$ & $517.6 \pm 333.4^{\mathrm{bc}}$ \\
& Lumbar* $^{*}$ Left & $100.0 \pm 0.0$ & $82.1 \pm 43.7$ & $307.4 \pm 173.7^{\mathrm{bc}}$ \\
& Cervical* $^{*}$ & $100.0 \pm 0.0$ & $128.9 \pm 52.3^{\mathrm{a}}$ & $269.3 \pm 114.0^{\mathrm{bc}}$ \\
& Thoracic* $^{*}$ & $100.0 \pm 0.0$ & $163.5 \pm 104.9^{\mathrm{a}}$ & $375.1 \pm 152.2^{\mathrm{bc}}$ \\
& Lumbar* & $100.0 \pm 0.0$ & $91.0 \pm 91.2$ & $329.3 \pm 246.5^{\mathrm{bc}}$ \\
\hline
\end{tabular}

$* \mathrm{p}<0.05$ by repeated ANOVA

a: Standing position $<$ Juchumseogi motion by paired t-test

b: Standing position $<$ Juchumseo Jireugi motion by paired t-test

c: Juchumseogi motion< Juchumseo Jireugi motion by paired t-test

muscle activation of the right and left $\mathrm{T} 7$ paraspinal muscle induced by Juchumseogi $(\mathrm{p}<0.05)$ and Juchumseo Jireugi motion $(\mathrm{p}<0.05)$ were higher than those induced by standing posture. Futhermore, muscle activation of the right and left T7 paraspinal muscle in Juchumseo Jireugi was significantly higher than that induced by Juchumseogi $(\mathrm{p}<0.05)$. In the right and left L3 paraspinal muscle, the muscle activation differed significantly from the postures $(p<0.05)$. The muscle activation of the right L3 paraspinal muscle in standing posture was $100 \%$; in Juchumseogi, it was $82.1 \%$; in Juchumseo Jireugi, it was $307.4 \%$. Muscle activation of the left L3 paraspinal muscle in standing posture was 100\%; in Juchumseogi, it was $91.0 \%$; in Juchumseo Jireugi, it was $329.3 \%$. The levels of muscle activation of the right and left L3 paraspinal muscles induced by Juchumseo Jireugi motion $(p<0.05)$ were higher than those induced by standing posture and Juchumseogi motion. But no significant difference of muscle activation was demonstrated between standing posture and Juchumseogi motion.

\section{DISCUSSION}

If Taekwondo should be developed to the level of a global sport, it is important to establish Taekwondo history and theory, nurture the development of Taekwondo experts, establish safe and interesting game operation guidelines, and verify the a positive effects of Taekwondo on the human body ${ }^{6,11,13)}$. Up to now most of the existing studies on Taekwondo have mainly focused on effective Taekwondo training methods and game operation methods in order to induce interest in the sport. Although it has been established that Taekwondo has a positive effect on the promotion of health, up to now studies verifying these beneficial effects have been insufficient. Therefore, this study examined whether an exercise program applying the basic motions of Taekwondo would exert a positive influence on the human body, particularly the paraspinal muscles. Generally, as the spine functions as a pathway of body and visceral nerves, an upright spinal posture is essential for human health. However, verification is required to establish that balanced development of elector spinae has a close relation with upright posture, and that the basic motions of Taekwondo may improve muscle activation of elector spinae. Juchumseogi (horse-riding stance) and Apseogi posture (walking stance) are basic lower limb postures in Taekwondo. Juchumseogi posture refers to a stance wherein a space between two legs at a width of two legs' length is achieved, bending the knees at an angle of 60-70 degrees, and standing upright under the paralleled condition of two legs by erecting the $\operatorname{shin}^{2)}$. At this time, the upper body is placed in an upright position and the sacrum is pulled backwards slightly while holding in the lower abdomen ${ }^{14)}$. Generally in standing posture, as lordosis of lumbar vertebra is increased due to passive straightening (stretching) of the iliopsoas muscle and contraction of elector spinae, muscle activation of elector spinae in lumbar vertebra is increased ${ }^{15)}$. Under this perspective, when the iliopsoas muscle is relaxed in a knee bending motion like Juchumseogi, lordosis of lumbar vertebra is decreased and muscle activation of elector spinae is reduced. In addition, in Juchumseogi, the upper limb is placed on the waist by lightly stretching the shoulder joint after bending the elbow joint at an angle of 90 degrees with clenched fists. At this time, as elector spinae of thoracic and cervical vertebra are required to be contracted in order to lightly stretch the shoulder joint, muscle activation would be increased. This study has demonstrated that muscle activation of paraspinal muscles of the lumbar area was lower in Juchumseogi posture than anatomical standing posture, even though no statistical difference was manifest, and muscle activation of the cervical and thoracic areas were statistically higher in Juchumseogi posture. Therefore, Juchumseogi posture reduces the tension of paraspinal muscles in the lumbar area and also enhances tension of paraspinal muscles in the cervical and thoracic areas. $\mathrm{Na}^{16)}$ reported that muscle activation of elector spinae while the knee joint is bent was higher than while the knee joint is in a straight position. Park ${ }^{17)}$ also reported that muscle activation of lower limb muscles under Juchumseogi posture was higher than that of elector spinae, but muscle activation of the elector spinae is also increased. As a result, Juchumseogi is considered to be a posture that enhances muscle activation of paraspinal muscles around cervical and thoracic vertebra. This study also confirmed that muscle activation of paraspinal muscles in the cervical, thoracic, and lumbar areas was increased more during Juchumseo Jireugi motion than during Juchumseogi posture. In connection with this result, $\mathrm{Kim}^{18)}$ reported that the effect of Juchumseo Jireugi on muscle activation of elector spinae was increased more when the body trunk was fixed by contracting elector spinae, 
compared to not fixing the body trunk. Hodges \& Richardson $^{19)}$ said that in order to remove unstable shaking of the limbs when moving the upper and lower limbs, body trunk fixation through contraction of lumbar extensor is required. These two studies have demonstrated that because instability of the limb is increased when doing Juchumseo Jireugi motion, strong lumbar extension is required in order to perform Juchumseo Jireugi efficiently. This study also demonstrates that in order to secure stability of the body trunk during moderate Juchumseo Jireugi motion, contraction of paraspinal muscles in the lumbar area is required. Therefore during Juchumseo Jireugi, muscle activation of paraspinal muscles in the lumbar area increased. This study has confirmed that Juchumseogi motion and Juchumseo Jireugi motion of Taekwondo increase muscle activation of paraspinal muscles and in particular, Juchumseo Jireugi motion is more effective for enhancing muscle activation of paraspinal muscles. So, when enhancing muscle strength of paraspinal muscles, an exercise program consisting of performing Juchumseogi and Juchumseo Jireugi motions is beneficial. The disadvantage of this study is that it failed to examine whether increase of muscle activation could directly affect muscle strength. Therefore, it is recommended that a future study researching the relevance of muscle activation with muscle strength increase be performed examining whether muscle activation and muscle strength increase are achieved after developing and applying an exercise program using Juchumseogi and Juchumseo Jireugi motions.

\section{REFERENCES}

1) Jung HD: A comparative analysis on the game contents of Taekwondo Karate and Wu-shu. Kyungnam University, Dissertation of doctorate degree, 2002

2) Kukkiwon: Kukki-taekwondo Manual. Osung Publishing House, 2006.
3) Lee JS, Han JW, Jee YS: Effect of Taekwondo career on the bone mineral density and body composition in juvenile athletes. Korean J Phys Educ, 2004, 13: 427-437.

4) Choi CS: Biomechanical analysis of the axial pre-rotational movement of the pelvis for the Jireugi in the taekwondo Juchumseogi stance. Seoul National University, Dissertation of doctorate degree, 2013.

5) Park JI: The Kinematic Analysis of Juchumseo Jireugi in Taekwondo. Korea University, Master's thesis, 2006.

6) Kang SC, Kim EH, Shin HM, et al.: A biomechanical analysis of four different Taekwondo body punch types in horseback-riding stance. Korean J Sport Biomech, 2007, 17: 201-208. [CrossRef]

7) Park YC: An analysis on biomechanics of Taekwondo body punch in horseback-riding stance. Yong-in University, Master's thesis, 2007.

8) Ahn JD: Picture Analysis of Motor Control's Property about the Motion of Stop-jirugi and Push-jirugi. The Korea Contents Society, 2008, 8: 224 252.

9) Lee HY, Kim HD, Lee SU: The effect of Juchumseo Jireugi in taekwondo speed of back extensor strength. J Sport Leis Stud, 2010, 42: 1077-1086.

10) Byun S, An C, Kim M, et al.: The effects of an exercise program consisting of taekwondo basic movements on posture correction. J Phys Ther Sci, 2014, 26: 1585-1588. [Medline] [CrossRef]

11) Park SY: The Study on Muscular Efficiency of Taekwondo Pumsae Juchumseogi. Dankook University, Master's thesis, 2012.

12) Yang J, Lee J, Lee B, et al.: The effects of elbow joint angle changes on elbow flexor and extensor muscle strength and activation. J Phys Ther Sci, 2014, 26: 1079-1082. [Medline] [CrossRef]

13) Park SR: A Study on Internal Value In 'Pumsae' of Taekwondo. Pusan National University, Master's thesis, 2008.

14) Shin SW, Lee JH, Lee EM: Study of riding stance. J Korean Qigong Med Soc, 2003, 7: 98-126.

15) Neumann DA: Kinesiology of the Musculoskeletal System Foundations for physical Rehabilitation. St. Louis: Mosby, 2002.

16) Na YC: Muscle activation analysis of erector spinae and rectus femoris depending on toe out angles in squat movement. Chungnam National University, Master's thesis, 2013.

17) Park SH: Biomechanical analysis of low extremity motion and the low back loading during squat exercise. Yonsei University, Master's thesis, 2011.

18) Kim KP: Electromyographic analysis of leg muscles ChuChumSugi motion. Research of sports science, 1991, 4: 123-135.

19) Hodges PW, Richardson CA: Delayed postural contraction of transversus abdominis in low back pain associated with movement of the lower limb. J Spinal Disord, 1998, 11: 46-56. [Medline] [CrossRef] 